\title{
Problemas da Elaboração e Contabilidade Orçamentária na Administração Pública
}

\author{
ABRAM NEY
}

\begin{abstract}
$\mathrm{O}_{\mathrm{s}}$
S orçamentos não são simplesmente questões de aritmética; antes, sob milhares de formas, penetram nas raízes da prosperidade dos indivíduos, das relações de classes e do poderio dos reinados. (Gladstone).

Para respondermos à pergunta: como fazer um instrumento para determinado fim - e, pode ser êle um instrumento para uma realização técnica qualquer ou um instrumento de administração, como o é um orçamento precisamos saber quais são as necessidades dêsse fim, para que possamos decidir como fazer o instrumento. Encontraremos neste documento a afirmação do princípio geral do trabalho de construção, isto é, a afirmação de que o conhecimento das necessidades, para cuja aplicação se faz o instrumento, equivale a mais de três quartos do problema do projeto da construção.
\end{abstract}

Assim, vamos lidar com:

a) a natureza de um orçamento e os fins para os quais é feito;

b) a técnica do orçamento consoante os fins orçamentários.

\section{I - A NATUREZA DO ORÇAMENTO E OS FINS PARA OS QUAIS É FEITO}

Ante a leitura de opiniões sôbre um assunto de aspectos múltiplos como é um orçamento, poderá vir à lembrança a fábula dos seis indús cegos que encontraram um elefante e o definiram, cada qual, de acôrdo com a parte do corpo do animal que puderam tocar. Quando seus olhos se abriram e cada um deles pode ver o animal em corpo inteiro, já haviam, em equipe determinado a sua natureza.

Alguns estudiosos de direito administrativo julgarão que a elaboração orçamentária é um fenômeno específico da administração pública, sobretudo naqueles velhos países - como o meu, a Inglaterra e a França - onde existe uma antiga tradição de feitura de orçamentos públicos, para autorização de dispêndio, pelo Parlamento, em prol dos planos e da despesa pública do govêrno.

Peritos em finanças públicas, por vezes, parecem inclinados a restringir a significação da elaboração orçamentária ùnicamente ao financiamento; o orçamento, nesse caso, não seria mais do que uma soma de despesas projeta- 
das a serem comparadas com a receita antecipada. Alguns deles, - e a prática em alguns países (mas não no meu) - defendem o método de unificação de tôdas as despesas, seja com bens capitais, seja com serviços, num só orçamento. E' possível que tenham sidc influenciados pela tradição da época em que - conforme observa a Professora Dra. Ursula Hicks - a técnica da contabilidade era ainda muito insuficientemente desenvolvida, pois esquecem pelo menos um dos princípios básicos do financiamento seguro. Não é a mesma corisa financiar investimento em bens capitais - meios duráveis de produção - que proporcionam, por muitos anos a possibilidade da produção de utilidades essenciais à vida social, e financiar despesas correntes, que criam, em seus propósitos produtivos, utilidades que não duram mais do que alguns dias cu semanas. Nesse particular, o Relatório Hoover de 1950 (sôbre a Organização do Poder Executivo do Govêrno) está do lado daqueles que defendem a divisão em duas categorias essenciais:

a) despesas correntes operacionais e

b) investimentos em bens capitais.

Assim tem sido, em minha própria experiência e, assim se tem verificado com os princípios da reorganização da administração pública da Holanda, após a guerra e a ocupação inimiga (1940-1945).

Por outro lado, os economistas e homens de negócios acostumados a usar orçamento como instrumento de administração (especialmente para a fixação das partes funcicnais da responsabilidade relativa à execução eficiente dos planos comerciais, no que se refere quer aos resultados quer aos custos), inclinam-se a dar demasiado ênfase à importância do contrôle da eficiência . Isto é, falam como se êsse contrôle das tarefas funcionalmente descentralizadas retivesse em si tôda a significação da elaboração orçamentária. Entretanto, tal não ocorre, embora a utilidade dêste instrumento de administração não possa ser negada e não possamos evitar o seu emprêgo para uma administração acertada (tanto de emprêsas privadas como de organização pública). A elaboração orçamentária tem um campo de utilidade muito maior do que o contrôle de direção considerado isoladamente, quer na administração pública, quer na privada. Não há - em minha opinião - confusão de princípios de administração pública, ha observância da similaridade de orçamentos, como instrumentos de direção, em ambas as administrações. Por outro lado, o conhecido autor americano, ALvin HANSEN, observa que ocorre tal confusão quando se aplicam, aos órgãos governamentais, cs mesmos preceitos de teoria e prática financeiras que são aplicados aos negócios privados ( $p$. 186/9 - "Política fiscal e ciclos de negócios"). E' necessário prestar atenção a essa afirmativa porque muitas pessoas partilham desta cpinião. O financiamento é uma parte - e talvez uma parte muita importante - das administrações.

Cumpre ao financiamento fornecer o dinheiro e os meios capitais para a obtenção das necessidades de qualquer serviço. Não acontece o mesmo em

(1) Relatório Hoover, p. 40, ed. BcGraw Hill, 1950. Orçamentos da Holanda e milhares de notas, $1947,1948,1949$ e.v. 
administração, quer tenhamcis de fornecer os meios para a inversão em bens capitais duráveis por muitos anos e decênios (de acôrdo com seu tipo e sua duração técnica ou econômicas), quer tenhamos de fornecer o dinheiro para o pagamento de salários semanais ou mensais cu para adquirir estoques cada trimestre ou semestre para emprêgo regular na continuidade do processo de produção. Vemos aí a diferença principal entre o orçamento de capital e investimento - (ou extraordinário), de um lado, e, de outro lado, o orçamento de exploração. Trata-se de umá distinção muito bem conhecida nos países europeus e defendida por muitos autores. A conseqüente aplicação da distinção entre os orçamentos de capital e o corrente e suas consequêencias na contabilidade leva à adoção do sistema de partidas dobradas na contabilidade pública. O sistema de partidas dobradas foi introduzido na Holanda após a libertação, em 1945, sob a responsabilidade ministerial do Professor P. Lieftinck. O sistema proporciona a plana aplicação do método econômico de elaboração orçamentária e contábil introduzido pelos contadores modernos nas grandes firmas. E, portanto, mais do que um sistema de avaliação que mostre apenas o aumento ou o declínio da solvência do Estado. Este sistema oferece um pancrama completo da posição financeira e econômica do Estado quanto ao equilíbrio entre o valor do ativo (bens capitais) e os direitos capitais, de um lado, e o volume do passivo e o capital em dinheiro, de outro lado. Pode - sistema distinguir (de acôrdo com os princípios de URSUla Hicks) entre as dívidas ativas e as dívidas passivas, mostrando também a divida morta; pode distinguir o ativo que produz uma utilidade, bem como uma renda em dinheiro e ativos de auto-liquidação. Distingue o ativo e os direitos após a liquidação. A recapitulaçảo da situaçãa a ser alcançada pela execução da política - planejada no orçamento - pode ser mostrada na projeção de um balancete no fim do período orçamentário. A situação que efetivamente foi alcançada é indicada no balancete ao fim do período compreendido pelo relatório.

Pode-se observar que seguimos aqui, em grande parte, as idéias do Relatório da Comissão Sueca de Desemprêgo, de 1931 (Secretário Dr. Dag Hammarskyold), exposta na "Teoria do Dinheiro e do Capital, 1939", de ERIK LiNDHAL, e minhas próprias experiências no serviço do P.T.T. da Holanda, com a aplicação das teorias de economia industrial do Professor Dr. $\mathrm{T}_{\mathrm{H}}$. LIMPERG. (O projeto da reorganização da elaboração orçamentária e da contabilidade do Estado foi feito durante a ocupação.) Em obras americanas encontramos uma breve nota elogiosa sôbre o sistema de partidas dobradas na contabilidade governamental em "Finanças Públicas, 1948", de ALFRED BUCHLER. O Relatório HoOver recomenda (re. 2, p. 40) a contabilidade de avaliação e a separação das inversões de capital das despesas correntes. E' minha opinião que um sistema eccnômico completo adapta-se sobretudo aos países que dependem de empréstimos estrangeiros para seu desenvolvimento.

No que diz respeito a esta distinção, não há uma verdadeira diferença entre a elaboração orçamentária e a contabilidade na administração pública e nas firmas industriais privadas. Fazer distinções neste setor corresponde a fechar os olhc's à verificação das diferenças efetivas, que são necessárias para 
a criação da teoria moderna das finanças públicas e da administração, que o Comité Hoover deseja.

A manutenção desta distinção não excluirá, conforme crê HANSEN, a possibilidade do financiamento, sempre que necessário, do deficit da exploração por empréstimos, nem do financiamento, sob certas circunstâncias, dos investimentos de capital retirado de rendas correntes. A distinção principal só exclui a confusão nos custos pelos investimentos mistos com despesas correntes. Além disso, exclui a confusão de custos (consumo de estoques) com sua aquisição. A tradição está colocando as despesas de aquisição scb os títulos principais errôneos, como se fossem custos. A principal distinção em pauta exige que, tôdas as vezes que optemos por esta espécie de financiamento, principalmente excepcional (isto é, financiamento do deficit de um empreendimento por empréstimo), indiquemos no orçamento e na contabilidade o que na verdade estamos fazendo. HANSEN está formalmente certo ao dizer que nem os orçamentos nem a contabilidade nos indicam se as despesas públicas devem ser financiadas por empréstimos ou por impostos. Cabe aos orçamentos e à contabilidade refletirem apenas 0 que tencionamos fazer ou o que temos feito. Não há, portanto, quem acredite que êstes instrumentos de administração possam fazer algo mais do que nos mostrarem o que é planejado ou o que é executado.

Quando enumerarmos, a seguir, as diferentes funções de um orçamento, poderemos expressar, de um lado, as funções que podem ser observadas na administração pública bem como na prática privada e, por outro lado, aquelas funções que são especificamente para a administração pública (as funções específicas nos negócios privados não oferecem interêsse algum ao presente estudo).

\section{Planejamento para administração}

a) Um orçamento é um plano para administração durante um determinado período futuro de produção. Um americano perito em orçamentos comerciais qualificou esta função como "uma contabilidade em têrmos do futuro". Esta função é a conseqüência do fato de que a administração de todos os tipos de produção - quer de utilidade pública como de mercadorias vendáveis, é uma previsão de circunstâncias e condições futuras antecipadas. Pode-se dizer que isso occrre, em parte, nos casos de produção por encomenda, mas, é plenamente aplicável à produção de mercadorias vendáveis, fabricadas em massa ou em grandes séries e também à produção de serviços de utilidade pública, quer por emprêsa particular, quer pelo Esțado ou por uma municipalidade. E igualmente aplicável a um grande número de casos em que o govêrno produz as utilidades de disponibilidade (ordem pública, defesa nacional, corpo de bombeiros, polícia, etc. ). E' aplicável - e mesmo requerida - sempre que cumpre à administração controlar o consumo eficiente de meios de produção (ou de suas unidades operativas, como é o caso de homens e máquinas) para a produção de bens ou serviços. E' necessária porque a própria administração racional exige para o conhecimento - "a priori" do consumo exigido. Como se trata de um plano, o orçamento público exprime 
projetos para um ou mais anos de execução por parte do govêrno do programa da maioria governante; o programa que o torncu vitorioso na campanha eleitoral (exceto aquelas execuções que são tão necessárias que não podem absolutamente ser objeto de política). Este fato cria a necessidade de aprovação do orçamento do Estado pelo Parlamento.

\section{Fixação ou determinação de tarefas}

b) Um orçamento é também um fixador de tarefas para a própria alta administração, sendo o responsável pelo processo da produção como um tcdo, seu prestador de contas e responsável por tôdas as funções descentralizadas que devem desempenhar um papel - em nível maior ou menor de autoridade - para a execução eficiente. Estas respcnsabilidades derivadas podem estar associadas à produção, no sentido técnico executivo, ou a funções administrativas ou comerciais, ou mesmo a funções de atividades auxiliares. $O$ orçamento, em suas funções de fixação de tarefas, é o fator fundamental de contrôle da eficiência. Permite à administração aplicar uma descentralização funcional em plena fórma sem diminuir a possibilidade do cumprimento de sua própria alta responsabilidade. Outrossim, orçamentos fixadores de tarefas criam, neste sentido, um alto grau de perfeição. Ainda a êste respeito, a distinção entre o orçamento de investimento de capital e de exploração é impcrtante. Apraznos ter a confirmação de ALVIN HANSEN. Sòmente os orçamentos da administração pública são elaborados com quase um ano de antecedência (três a seis meses de preparo e de cinco a seis meses para debates parlamentares), razão pela qual queremos, na administração pública, medidas especiais para a salvaguarda da eficiência do contrôle. Neste ponto encontramos a observação de ARTHUR SMITHIE em sua obra "Elaboração orçamentária federal e política fiscal". Além disso, temos a nova prática governamental holandêsa de orçamentos especiais de fixação de tarefas (introduzida em 1946) para solucionar a dificuldade de que fala SMrTHIE. (2) Mas, a fixação de tarefas quando feita o mais corretamente possível - exige que os custos padrőes sejam expressos por unidade de execução ou unidade de tempo, a começar do grau normativo de perfeição na produção da tarefa ou do produto de serviço. Dispensaremos atenção ao estabelecimento dêsșes padrões posteriormente.

\section{Contrôle de execução}

c) Um orçamento, como visa a fixação de tarefas, estabelecido numa cocperação estreita com as pessoas responsáveis por sua execução, em seu todo e nas partes orgânicas, é, simultâneamente, um instrumento para controlar a execução quanto à legitimidade e à eficiência. A legitimidade diz respeito à competência dos executores das partes orgânicas; a eficiência refere-se à restrição da quantidade e qualidade de sacrifícios aos quais está tècnicamente

(2) Comparar com meu artigo As transfornações da contabilidade pública na "Revista Internacional de Ciências Administrativas", 1951, N. 3. 
obrigada ou que são, econômicamente, inevitáveis. Êste padrão abre a pussibilidade - quando comparado aos sacrificios reais - de estabelecer as diferenças entre os custos antecipados e os efetivos ou as rendas previstas e efetivas. Analisando as causas dessas diferenças torna-se possível descobrir se há alguma falha cu negligência no que se refere à eficiência de execução ou à percepção de rendas e, por outro lado, pode haver condições ou circunstâncias modificadas de natureza acidental ou permanente. No último caso, pode haver a necessidade de modificação para o próximo período üçamentário. No relatório HOOVER esta verdade é assinalada ràpidamente com a seguinte frase: "A elaboração orçamentária e a contabilidade andam de mãos dadas". "Sòmente mediante confrontos entre atividades similares e da mesma atividade de anos diferentes pode-se submeter a eficiência a uma prova". Cumpre assinalar o fatc de que, nessas comparações, devemos calcular os valores dos períodos em questão.

Observemos agora que as três funções acima indicadas são de natureza exclusivamente administrativa. São necessárias para os fins internos da direção. Quer se trate de uma única fábrica ou de um único serviço público ou privado; quer se trate de um inspetor geral de um exército ou das fôrças aéreas. Elas são igualmente necessárias ao chefe de um departamento que tenha muitos serviços sob sua responsabilidade, ou ao presidente de um Estado, responsável por todo o programa orçamentário, ou ao presidente de uma firma industrial. Nestas funções observamos o crçamento como um instrumento de direção. Aventuro-me a dizer que o orçamento é do mesmo tipo de utilidade de direção, com referência à criação de uma diretriz e de sua execução eficiente que um instrumento de análise e apreciação de emprêgos nas questões de administração de pesscal.

\section{Coordenação}

d) Sòmente quando os orçamentos são usados a fim de orientar e dirigir coletividades de produção sob uma responsabilidade centralizada desempenha o orçamento uma outra funçãc, ou seja, a de coordenação de plano dos diferentes serviços sob a mesma responsabilidade. Podemos observar que esta coordenação pode ser encontrada em diferentes fases de estratificação, por exemplo: ministerial;

$1^{\circ}$ ) a coordenaçãa de planos de serviços sob uma responsabilidade

$2^{\circ}$ ) a coordenação dos orçamentos dos diferentes ministérios sob a responsabilidade do Presidente do Estado ou do Gabinete.

Esta quarta função é ainda de natureza administrativa relacionada com o contrôle da produção. A natureza orgânica do Estado - como se fosse um orçamento de emprêsa - foi exprimida pelo inspetor geral do exército francês, R. JACOMET, nas seguintes palavras: "L'administration d'un Etat aux activités aussi étendues et dispersés et qui prélève sur la collectivité un tribut de plus en plus lourd, doit témoigner - par le souci constant d'une organisation rationelle de ses services - de son aptitude à fournier au public le maxi- 
mum de satisfaction au mcindre drix de revient. Il est donc indispensable, qu'elle se préoccupe désormais de déterminer le coüt réele chacune de ses activités ainsi que les changements de valeur des richesses de toute nature dont elle fait usage pour remplir des missions".

A mesma idéia é manifestada no relatório sueco acima mencionado veja o livro de ERIK LINDAHL. Esta idéia foi também um objetivo da reorganização administrativa da Hclanda em $1945 / 50$ sob a responsabilidade do Ministro Lieftinck.

O Relatório HoOver expressa a mesma opinião na recomendação n. ${ }^{0}$, p. 36. "Recomendamos que todo o conceito orçamentário do Govêrno $\mathbf{F e}-$ deral seja remodelado pela adoção de um orçamento baseado em funções e projetos ao qual denominamos "orçamento de execução" (um novo sistema de orçamento apresentando o custo de operação, a fim de que o Corgresso possa, prontamente, confrontar êste custo com o do ano precedente ou com Cis custos de outros serviços comparáveis)". "Um orçamento de execução não modifica nem desvia a responsabilidade legislativa; presta uma informação mais completa e fidedígna e auxilia os congressistas a compreenderem os atos do govêrnc". Tôdas as funções produtivas devem ser calculadas em valôr e se relacionarem aos custos e rendas.

\section{Financiamento}

e) O financiamento da produção é uma função derivada, de natureza direcional, mas, não no sentido técnico e administrativo. E' uma função de fornecimento de dinheiro e de capital (investimento) a fim de tornar disponíveis os estoques necessários de meios de produção (estcques de unidades de materiais para produção, estoques de mercadorias para aquisição no comércio privado, estoques de unidade de trabalho de homens em tôdas as categorias de trabalho, estoques de unidades de trabalho, de máquinas de trabalho, máquinas de fôrça, edifícios, etc. ).

O financiamento relaciona-se, por um lado, com as receitas decorrentes da exploração do serviço (ou de uma coletividade de serviços diferentes sob uma responsabilidade coletiva central, como no caso da produção estatal, e da coletividade de utilidades disponíveis). Por outro lado, relaciona-se com as despesas do fornecimento dos estoques acima mencionados ou melhor com o fornecimento de sua renovação regular. A administração estável, principalmente no que se refere a êsses assunto, deve dispensar atenção ao fato já mencionado de que as receitas correntes servem para ccibrir os custos, uma vez que são equivalentes aos custos correntes da produção dos serviços (quer sejam recebidos em unidades ou num só pagamento para uma coletividade). Mas, na produção moderna, que exige a aquisição de imensas quantidades de bens capitais (como se fosse por concussões), há uma diferença entre as despesas periódicas das aquisições de estoques e, por outro lado, o seu uso, que decorre com a mesma regularidade da produção. Esta diferença requer correções regulares de valor na administração do estoque em todos os momentos importantes de mudança de valor (cálculo no valor substitutivo). 
Um princípio geral é o de que os custos consistem do valor (mais precisamente: valor substitutivo) das unidades necessárias de matérias-primas, das unidades necessárias de trabalho humano, das unidades necessárias de máquina e instalações (excluindo a capacidade disperdiçada que representa prejuízo). O fator mencionado por último pode ser definido como sacrifícios da disponibilidade de capacidade e compreende: depreciação, aluguel e manutenção. Entretanto, sòmente aquelas partes sacrificadas que representam as unidades de trabalho efetivamente necessárias para a pradução corrente podem ser consideradas como custos. O restante deve ser considerado como prejuízo. (3)

Outro princípio geral é o de que as novas aquisições dos meios duráveis de produção devem ser propurcionadas por investimentos - empréstimos com a diferença que, nos negócios privados êste investimento exige principalmente ações e, nos casos de serviços estatais e de emprêsas do Estado, o investimento se faz apenas em títulos. O financiamento de substituição é consequiência do cálculo da depreciação, de modo que - falando genèricamente os bens capitais a serem substituídos num determinado período podem ser financiados pelas quantias calculadas para a depreciação durante aquele ano. Eis ai outro argumento para o cálculo do valor substitutivo.

Os orçamentos de financiamento são tão necessários na administração pública como nos empreendimentos particulares, mas são da maior importância no primeiro caso, porquanto aí estão associados ao bem estar geral.

\section{Autorização}

f) Ccm o nosso último argumento no terreno especial da elaboração orçamentária pública. Sendo o Govêrno - segundo os princípios democráticos modernos - a mais alta representação da unidade nacional, o maior poder autorizador reside na representação parlamentar. Exerce o Parlamento o poder legislativo e, portanto, a tarefa de aprovar, antecipadamente, os planos do Govêrno para um ou dois anos. Como nenhuma outra fórma de produção requer tal superestrutura, vamos encontrar esta aprovação dos planos expressa apenas nos orçamentos da administração pública. A êste respeitc, estudiosos tradicionais do direito administrativo restringem seus contatos com nosso problema e mutilam, portanto, os princípios e a técnica orçamentários. Assinalamos aqui que é a superestrutura que cria a função especial da autorização orçamentária. Ela já foi apresentada acima, em alguns aspectos, em sua conexão com outras funções gerais.

De um modo geral, a autorização considera o plano governamental como um todo - explcração dos serviços e seus financiamentos - e não se restringe apenas ao financiamento. Há, porém, uma antiga incompreensão que limita a autorização ao financiamento. Ela remonta aos tempos em que a produção (e a exploração de serviços) não exigia meicss permanentes de produ-

(3) Veja o relatório Orçamento Flexível e Variável. Dr. ABram Mey e E. MeEkman, Congresso em Mruxelas do C.I.O.S., 1951. 
ção, sobretudo no terreno restrito das atividades governamentais do século XIX. Além disso, havia uma curiosa incompreensão que considerava tais atividades ùnicamente de consumo e não percebia que tôda a produção é apenas o aspecto inverso do consumo, como a produção é um consumo eficiente de mercadorias e serviços valiosos para a produção de outros mais valiosos ainda. O consumo final nada mais é do que a reprodução das unidades de trabalho da atividade humana. Portanto, o consumo que não cria produtcs é um disperdício. Um govêrno produz fatores básicos (utilidades de disponibilidade) para a vida social de uma nação e seu desenvolvimento produtivc. Naturalmente, isso consiste em produção para a qual pagamos impostos, por vezes destinados a serviços determinados, por vezes para todos os demais serviços considerados como uma coletividade.

\section{Orçamento de execução (custos segundo uma estrutura orĝânica)}

g) Releva lembrar a máxima de Jacemot segundo a qual os contribuintes de impostos devem estar cientes da eficiência da produção de cada um dos serviços para que a atividade do govêrno seja uma resposta às suas obrigações básicas. Mas, como será isso possível quando o orçamento é feitc com um ano de antecedência; os preços (e, conseqüentemente os valores substitutivos) podem decrescer, ou um método mais eficiente de produção de um serviço tornar-se possível? Não é pelo fato da autorização visar, primeiramente, o plano e não ser uma ordem para o dispêndio de numerário que uma adaptação autcmática, para uma execução mais barata e mais eficiente deve ser introduzida. Eis aqui um problema que resolvemos na Holanda mediante o estabelecimento de orçamentos de fixação de tarefas (que são ao mesmo tempo instrumentos para o contrôle de eficiência em épocas de aumento de preçcs). O Ministro da Fazenda é nomeado por prescrição legal para controlar a eficiência de todos os custos na administração do país e, assim, ao mesmo tempo, para coordenar todos os graus de perfeição de todos os planos projetados e a execução dos mesmos. Assim sendo, todos os serviços devem ser especialmente aprovados por êste Ministro (e, no seu impedimento pelo Diretor do Orçamento) antes que possa ser ordenada a execução de qualquer serviço público acidental ou antes que o custo de sua exploração referente a um mês vindcuro possa ser dispendido. Há também orçamentos acidentais de fixação de tarefas (ou como são oficialmente chamados: aberturas de crédito) assim como orçamentos periódicos. A fórmula para a elaboração dêsses orçamentos mensais para meses vindouros é combinada $\mathrm{ccm}$ a do balanço experimental do mês anterior. Assim sendo, a contabilidade não se pode atrazar.

Outrossim, todos os mêses, o diretório do orçamento pcde determinar, para o tesoureiro, mediante êsses orçamentos fixadores de tarefas, um orçamento de caixa digno de confiança. Neste sistema a contabilidade pcde ser descentralizada - tal como o requer o plano Hoover - sem provocar complicação ou diminuição do poder dos postçs centrais de comando do financiamento. Devido ao fato de todo serviço apresentar um estudo inicial do seu própria orçamento para autorização, assim ccmo o projeto de seu orçamento 
de fixação de tarefas para aprovação pela inspeção do serviço de orçamento, o sistema de orçamento tem por alicerces a estrutura orgânica. Pela mesma razão, o sistema de contabilidade tem uma estrutura crgânica; cada serviço tem seus próprios livros mestres. Além disso, um sistema normalizado contábil e de itens orçamentais é criado para classificar as categorias de preços (expressas em código decimal) o qual proporciona a possibilidade de adição de tôdas as categcrias de custo de todos os serviços sob um mesmo departamento e mesmo a adição dos mesmos tipos de custo para todo o aparelho. Pode ainda ser aplicado quando tôdas as autoridades locais empregam a mesma estrutura contábil e oferece a possibilidade - se governus cooperadores o quiserem fazer - de criar números comparáveis para uma cooperação federativa entre as nações. Livros mestres que apresentam um balanço próprio completam o sistema contábil. Os livros mestres dos serviços têm relação com o livro mestre da seção de contabilidade de seu ministério e os livros mestres dos ministérios se relacionam com o livro mestre geral que se encontra no diretório do orçamento, constituindo uma seção especial. E, assim é o sistema de relatório; balanços experimentais devem ser enviados pelcs serviços até dez dias após o fim do mês ao contador de seu ministério, e o contador deverá enviar seu balanço experimental, no prazo de vinte dias, ao contador geral. Dêste moda, o orçamento e a contabilidade estatais satisfazem tôdas as funções do orçamento e contabilidade públicos. E' um instrumento da administração, uma base para o contrôle da eficiência e uma fundação para proporcionar a todo funcionário aquele senso de respcnsabilidade embora restrita - baseada em confiança em si próprio, que constitui uma condição para o gôzo de sua atividade e função na organização considerada ccmo um todo.

II - A TÉCNICA DE ELABORAÇÃo DE ORÇAMENTO DE ACÔRDO COM OS PRINCíPIOS EXPOSTOS

Agora que já sabemos quais são os fins a as funções dos orçamentos considerados como instrumentos da administração, de acôrdo com os modernos especialistas em orçamento e eccnomistas de administração pública, poderemos ser relativamente suscintos na análise das técnicas para a elaboração de orçamentos.

\section{Métalos técnicos errôneos}

Vejamos, inicialmente, as técnicas erradas que podem ser deparadas na prática tradicional. Seria, por um lado, uma técnica errada tentar impôr o orçamento acs responsáveis pelos serviços, numa violação clara de hierarquia. Essa prática estaria em perfeito desacôrdo com as bôas práticas de administração, em contradição ainda com a análise psicológica. Por outro lado, não se deve esquecer que os diretores de serviços se acham, geralmente, inclinados - e, muitas vezes mesmo farçados - a projetar a execução de seus serviços num alto grau de perfeição. Mas, se êsses projetos são considerados no orçamento final, a extensão das despesas ultrapassaria - no tocante a tôdas 
as utilidades de disponibilidade - as possíveis arrecadações ou se as rendas fiscais fossem adaptadas a essas exigências exageradas, aquele custo excederia as despesas a que a nação pode fazer face. Deveremos tentar encontrar um método de coordenação dos interêsses técnicos dos chefes especializados de serviços e dos interêsses centralizados de financiamento seguro, visando alcançar estruturas financeiras seguras para a nação e uma execução eficiente das funções oficiais.

Entramos então no campo de um outro método errado; muito conhecido na prática da contabilidade pública. Consiste em determinar o orçamento de um ano vindouro como uma simples modificação do orçamento de anos anteriores. Como poderá tal orçamento, que exclui a verificação dos itens orçamentários mediante comparação de números no decorrer do tempo, jamais servir de base para o ccntrôle da eficiência? A apresentação ao Parlamento de um orçamento elaborado desta maneira nada mais é que um pedido de autorização para cometer os mesmos êrros de administração perpetrados em anos anteriores. Seria apenas a solicitação de uma concessão para uma administração tão ineficiente e livre de crítica como a anterior. No que se refere a êsse ponto, podemos concluir que, uma elaboração racional de orçamento requer o cálculo de sacrifícios inevitáveis em qualquer produção. Em outras palavras, exige contabilidade de custa.

A comparação entre itens de ancs sucessivos só tem valor se os respectivos números forem calculados independentemente uns dos outros; pelo menos quando os itens se referem a custos variáveis e a custos que dependem da eficiência da execução dos serviços. Assim acontece com despesas de pesscial (mesmo com pessoal regular de serviço porque de seu número depende a eficiência da execução).

Um outro perigo existe ainda no método de elaborar orçamentc's baseados em dados obtidos de orçamentos anteriores. "Quando" - como observa a Sra. Hicks no seu livrc "Public Finance" - "uma tendência à elevação de custo é observada, é fácil obter a votação para uma extensão dos serviços públicos em tempos favoráveis; uma vez estabelecido um serviço, êle tende naturalmente a crescer. Aqui se encontra o período - sobretudo em tempc's de prosperidade crescențe - a comunidade se provê com um maior número de bens públicos - ou meios de os produzir - ou com mercadorias num grau por demais elevado de perfeição do que se torna necessário ao bem geral". Nessa caso a Sra. Hicks recomenda dois métodos; ambos condizentes com a minha experiência prática. Em primeiro lugar, uma verificação da eficiência (mas, assim sendo, desejo um cálculo normativo e custos padrões) e, em segundo lugar, uma determinação dos limites de uma expansão prudente e as prioridades corretas entre exigências competidoras dirigidas aos recursos nacionais (coordenação de planos). A mesma dificuldade se depara na estimativa de receitas sem que seja feito um novo cálculo da receita nacional para o perícdo vindouro (em outras palavras, da receita decorrente das fontes de bem-estar do país durante o ano enquadrado no orçamento), deverá ser considerado impossível preparar uma estimativa da receita fiscal que mereça confiança. A veracidade desta asserção se torna perfeitamente clara para 
todos aqueles possuidores de alguma experiência no tocante a ciclc's de negócio, desenvolvimentos estruturais, etc.

Passemos a seguir ao campo conhecido como contabilidade e orçamento nacionais (istc é, o cálculo prévio e posterior da receita nacional). Os nomes de U. Hicks, R. Stone, Dercksen, Tinbergen, Lindahl e muitos outros achamse ligados a êsse problema. No nosso país, foi política do Ministro Lieftinck apresentar o orçamento do Estado - a partir do primeirc momento da libertação - sôbre as bases dêsse orçamento nacional.

\section{Números alvos}

O fato de tentarem os chefes de serviço alcançar um grau de perfeição bastante elevado, na execução de seus serviços, exige - coma já vimos uma medida de coordenação. O cálculo de números alvos para o custo total é o primeiro passo que um ministro pode dar quando procurando atingir um orçamento comum equilibrado (receita fiscal em oposição a despesa).

Entretanto, os números alvos podem apenas ser indicados de maneira justificável se tiverem como base a contabilidade de custo. Na sua falta, aqueles números constituem, sobretudc, especulação e não alvos reais. Números alvos são especialmente necessários quando novas medidas são projetadas, como modificações aos orçamentos já existentes. Seria muito avisado se cada lei incluisse, no último artigo, um cálculo "a priori" do custo aproximado. E, assim acontece com cada emenda do Parlamento tentando elevar o grau de perfeição no qual uma utilidade de disponibilidade é produzida; quer na discussão do orçamento ou no tratamento parlamentar de um determinado ncvo projeto. Podemos concluir que a contabilidade de custo é inevitável ao orçameno moderno; ou -- exponhamos melhor o nossa problema na administração pública moderna, no tocante à direção interna da administração, assim ccmo na direção externa do projetamento de orçamentos para autorização, ou o estabelecimento de relatórios anuais, relativos aos resultados da execução dos planos autorizados. Como é fato conhecido, a administração pública - mesmo no sistema de partidas dobradas - não possue contabilidade de renda no mesmo sentido que uma emprêsa. Mas, a administração pública pode apresentar um relatório de contabilidade quanto aos resultados de sua execução:

a) para aqueles serviços que produzem utilidades para uso público tais como estradas de ferro, serviços postal e telegráficc - aquela contabilidade compara recibos de tráfego, etc., com os custos requeridos (e também custos padrões com os sacrifícios reais, se possível).

b) para aqueles serviços que provêm utilidades de disponibilidade, mas que não possuem receitas destinadas a cobrir os custos, os relatórios de contabilidade, relativos ao custo de cada um dos diferentes serviços, (se possível, apresenta uma comparação de custos padrões dos serviços com os custos reais), e compara o custo total de todos cs serviços com as rendas destinadas a cobrir a produção de disponibilidade. 


\section{Princípias de contabilidade de custo}

O custo de qualquer serviço ou produto pode, geralmente, ser definido como: as quantidades tècnicamente requeridas ou econômicamente inevitáveis para produzi-los, calculadas mediante valores substitutivos, inclusive juros sôbre o financiamento do poder de adquisição compreendido nos estoques, meios permanentes de produção, etc., na medida que se acham ligados com o produto ou o serviço em questão. Pode ser expresso segundo a teoria de Limperg (4) pela fórmula:

$$
C=Q \times V \times\left(1 \div \frac{p}{100}\right)^{2}
$$

$\mathrm{C}=$ custo

$\mathrm{Q}=$ quantidade necessária ou inevitável

$\mathrm{V}=$ valor substitutivo no momento da produção

$\mathrm{p}=$ fator juros

$\mathrm{t}=$ fator tempo.

Conforme indica a definição, as quantidades dependem das exigências técnicas e dos fatores eccnômicamente inevitáveis, tais como, por exemplo, as inevitáveis flutuações resultantes do efeito das estações sôbre os hábitos de produção, flutuações que se refletem na qualidade dos materiais, flutuações no tempo de trabalho decorrentes da variação de habilidade e fadiga, etc. O ponto mais importante nessa concepção consiste em ser a fórmula também aplicada ao custo dos meios permanentes de produção dentre os quais são calculados como custo o número de unidades de trabalho requeridas ou ine. vitàvelmente sacrificadas na produção. Assim, o custo de meios permanentes de produção varia em função da extensão da produção; a capacidade estéril já foi contabilizada como perda no decurso do período anual.

O valôr de qualquer produto ou serviço é o preço de seu custo no momento crítico de venda (quando o pedido é aceito e o preço fixado para a produção encomendada ou quando o produto é entregue do estoque de produção em massa). No tocante à produção de utilidades de disponibilidade, Essa definição é modificada da seguinte maneira: o valor do serviço num determinado período é o preço de custo no momento de disponibilidade.

A quantidade de materiais requeridos, horas de trabalho humano, horas de trabalho das máquinas, etc., dependem da qualidade ou grau de perfeição de fabricação do produto $\mathrm{cu}$ de prestação do serviço fornecido. Chamamos a isso o grau padrão de perfeição. Um padrão de perfeição demasiadamente elevado para um produto, uma freqüência elevada demais, um grau de luxo muito elevado para o equipamento de um serviço colacarão o preço de custo

(4) O Professor LIMPERG foi meu predecessor na presente função por mim exercida, e desenvolveu um sistema de teorias novas sôbre economia de mprêsas. 
acima do nível do preço - ou taxa no qual um número de produtos ou serviços podem ser fornecidos, o que é suficiente para elevar a ceupação da capa cidade disponível a um nível remunerativo. A administração tem de estar ciente do efeito no preço de custo provocado por alterações no grau do perfeição. Para serviços estatais, tais como ferrovias, serviços postais, etc., a base da taxa é o preço de custo por unidade, por exemplo: o transporte de un passageiro, num compartimento comum de terceira classe, a uma distância de $100 \mathrm{~km}$, a uma velocidade padrão, com um número de paradas, etc.. num trem de composição padrão. A fim de calcular êsse preço de custo, devemos analisar o que se torna tècnicamente necessário (econômicamente inevitável) para aquela viagem padrão de $100 \mathrm{~km}$. Isso pode ser em parte calculado dıretamente (custos diretamente avaliáveis); pode ser parcialmente estimado quando analisamos a organização do serviço a fim de verificar como as dife. rentes sers̄os de organização se, relacionam com a viagem padrão (medidı indireta do custo necessário).

A fórmula acima mencionada é aplicável, com algumas modificações; podemos calcular a custo como a soma de custos necessários (ou sacrifícios inevitáveis) - quantidades $\mathrm{x}$ valores - para a produção do serviço num grau padrão de perfeição durante um certo tempo padrão. Outrossim, desejamos saber que modificação do custo se relaciona com alterações no grau de perteição da produção.

Quando efetuando o cálculo dessa maneira, por exemplo, o custo do exército, partimos do que se pode denominar a "formação padrão", número e tipos de regimentos (infantaria, artilharia, etc.), número de batalhões em cada regimento, etc., número de soldados, oficiais, etc., qualidade e quantidade de armamento, etc. Podemos calcular o custo da manutenção padrão de um homem ou de um oficial; c "custo padrão de uma unidade de trabalho" sle armamento (ciepreciação, juros, manutenção, etc.). E, como alguns dêsses padrões são expressos em dias, outros em mêses ou anos, convertemos todos à mesma unidade padrão de tempo.

E' possível, no exemplo dado, calcular desta maneira o custo padrão numa unidade de tempo para cada uma das armas, cada uma das divisões e das subdivisões. Da mesma maneira, podemos calcular o custo padrão de cursos dágua (um padrão de $100 \mathrm{~km}$ de canais de classes padrão de construção, com um númerc padrão de comportas ou sem comportas, etc.). Podemos calcular o custo padrão para cada distrito chefe de engenharia dos Serviços de Canais. Quanto ao trabalho humano nos escritórios da administração, podemos seguir - "mutatis mutandis" - o mesmo prccesso. Lembremos que o primeiro passo deverá consistir em analisar o trabalho de cada escritório a fim de estabelecer uma organização eficiente para o trabalho a ser executado. Uma reorganização peđerá ser necessária, e a padronização de trabalho recorrente é necessária. Análises de tarefas e avaliação de trabalho são métodos valiosos para - no curso do tempo - se chegar à determinação do tempo de trabalho necessáric para uma produção eficiente. Além disso, prever o tempo requerido para a preparação de decisões ministeriais será difícil, a princípio, mas, inevitável quando se deseja chegar a uma organização satisfatória de trabalho como a exigida pelo Relatório Hoover. 


\section{A técnica final de orçamento}

a) A exploração do orçamento comum - O cálculo de custo padrão exige a colaboração, de um lado, dos especialistas técnicos do serviço em aprêço, e. de outro lado, de economistas especialistas em cálculos (no nosso casc, funcionários públicos da Diretoria do Orçamento). Devido ao fato dos especialistas do serviço cooperarem no cálculo e também na determinação de padrões - é possível exigir dos chefes de serviços a elaboração de um anteprojeto do orçamento, quando partindo de um determinado grau de perfeição, que indique ao mesmo tempo os números alvos.

Então, o primeiro passo na cooperação $\mathrm{ccm}$ o Diretório do Orçamento será a verificação, pelo "inspetor de finanças" (funcionário do Diretório) da eficiência, etc., do projeto. O inspetor deverá apresentar um relatório sôbre as diferenças de opinião ac Diretor e ao Ministro competente, ao Diretor do Orçamento e ao Ministro das Finanças. O papel do inspetor na determinação do orçamento anual para fins de autorização facilita seu trabalho posterior de verificação mensal de orçamentos para fixação de tarefas.

Após c primeiro passo cada um dos Ministros tenta coordenar todos os projetos de orçamento dos diretores de seus vários serviços com o auxílio do relatćrio do inspetor. Nisso consiste o segundo passo da ccordenação.

Além disso, o Ministro das Finanças entrará em entendimentos com cada um de seus colegas, juntamente com seus respectivos funcionários chefes, a fim de fornecer o mesmo tipo de coordenação a todos os orçamentos.

Finalmente, os orçamentos são discutidos no Conselho de Ministros e estarão então prontos para serem apresentados ao Parlamento.

Um documento especial, versando sôbre a situação financeira do país e apresentando os planos será preparado para ser entregue a M.P. com o orçamento.

Como se tem conhecimento, antecipadamente, devido aos cálculos padrões, de quais serão as conseqüências, no grau de perfeição, decorrentes de alterações, modificações podem ser introduzidas no orçamento, sem dificuldade, durante sua discussão.

As estimativas de rendas decorrentes de impostos ou outras taxas depende das aproximações da receita nacional nos diferentes setores da vida econômica. Esse tópico já foi discutido. Devemos adicionar a êsse comentário, entretanto, que será necessário que modifiquemos essas estimativas durante o curso do ano, ş condições e circunstâncias denotam modificações duráveis. Se os impostos e taxas fluem em abundância, como acontece em períodos de prosperidade geral, a administração deve ter o cuidado de não se desviar de seus níveis de eficiência. Nesses períodos pode ser possível crear reservas destinadas a cobrir as exigências de períodos maus e, enquanto vivermos sob os efeitos de flutuações dinâmicas na vida econômica, não haverá necessidade de equilibrar o orçamento anualmente, caso os cbjetivos do govêrno pudessem ter sido melhor alcançados mediante seu equilíbrio durante ciclos de negócios. 
De um modo geral, modificações permanentes - quer no tocante a receita, quer quanto a custo - poderão dar margem a autcrização suplementares do Parlamento. Mas, isso não constitue problema.

b) $O$ orçamento de investimento - Já foi dito que uma diferença entre as duas partes do orçamento se faz mister; a substituição terá de ser financiada pelo fundo de substituição o qual é constituído pelas quantias calculadas para depreciação (em valores substitutivos). A depreciação é um fator de custo nos diferentes setores do orçamento comum; as quantias calculadas desta maneira aparecem como receita no orçamento de capital, cobrindo tanto quanto necessário as despesas de substituição. O equilíbrio aumenta ou diminui o fundo; no decorrer dos anos haverá um equilíbrio entre despesas de substituição e ccntribuições ao fundo de substituição (mesmo em épocas em que a inflação ou a desvalorização podem causar perdas na quantia conservada no fundo para substituição futura). Substituições podem ser adiadas durante períodos de prosperidade, a fim de serem efetuadas em períodos de depressão, como uma medida compensatória à política de ciclos de negócio.

No que se refere a novos investimentos (expansão de ativo, de bens capitais) teremos de discutir um novo problema. Alguns dêsses serviços públicos são executados num período de dcis ou três anos, outros exigem decênios, alguns um quarto de século ou mesmo tempo mais longo. Em muitos casos, o primeiro período da execução requer apenas um investimento reduzido em relação à extensão do serviço considerado como um todo. Nesse caso, é quase errôneo apresentar êsse primeiro período para autorização, pois que, posteriormente, nova aprovação será quase inevitável. Assim sendo, deveremos seguir um outro caminho na elaboração de orçamentos de capital. E' necessário informar o M.P. - em colunas especiais do fcrmulário do orçamento sôbre a duração do trabalho, a soma total necessária para a execução e a extensão técnica total do projeto, a quantia dispendida nos anos anteriores, a quantia indicada para autorização durante 0 ano em curso, e a quantia necessária para os anos futuros. Assim, êsse orçamento cresce tomando o aspecto de uma "loi de programme" (muito conhecida na contabilidade francêsa).

A autorização do primeiro perícdo agora inclue a aprovação provisional da execução do serviço total, mas não da sua temporização. Nesse novo investimento há, a saber, sobretudo um outro meio de compensação de ciclos de negócio, pois que a execução pode ser, quer retardada, em épocas de prosperidade, preços altos e emprêgo total, quer acelerada, em épocas de depressão.

\section{Observação final}

Existe ainda uma cutra dificuldade a ser observada nesse trabalho. Longo espaço de tempo deverá decorrer antes que se consiga prover ao aparelhamento da administração pública um grau de perfeição torne verdadeira e perfeitamente possível o seu emprêgo, como foi aqui descrito. Entrementes, será necessário ccmbinar os métodos tradicionais com o método novo e racional, mas, as principais deficiências dos métodos tradicionais já foram apontadas, assim como as imperfeições dos métodos recém-introduzidos tornando- 
nos, portanto, melhor equipadcs, durante o período de reorganização, do que estávamos antes de iniciarmos a reorganização. Deveremos prosseguir, a cada passo, na execução de um plano bem elaborado que poderá durar alguns anos. Dai decorrerão várias despesas antes que o plano seja executado, mas, êsses gastos representam bens-capitais, pois que os benefícios deles resultantes durarão muitos anos. Após haverem sido calculados cs custos-padrões e a modificação dêsses padrões através a variação do grau de perfeição, elaborar um novo orçamento, besseado nesses fatores básicos, será uma tarefa fácil; mais fácil mesmo que eiaborar um novo orçamento com modificações especulativas, baseado nas cifras do ano anterior. Da mesma maneira, depois de haver analisado o número e as classes de pessoal requeridos nos vários escritórics, mediante uma análise de serviço e uma classificação de trabalho, e haver anotado os resultados dessa investigação em gráfícor normalizados (sistema Hymans), torna-se muito fácil verificar a eficiência das modificações que os chefes de serviços propõem. A elaboração de orçamentos é, então, baseada em certos fundamentos, uma vez que os fatores básicos se achem à disposição dos chefes de serviços, do departamento central de administração de pessoal, do Diretório do Orçamento, a determinação de orçamentcos poderá ser efetuada com um mínimo possível de atrito entre as competências profissionais.

O benefício que disso resulta é a obtenção de melhores orçamentos. Outras conseqüências serão: a economia de gastos com exploração; proporcionar uma administração melhor e mais eficiente; proporcionar maior prazer no serviço que exercem as funcionários públicos; prover melhor informação para - Parlamento e uma maior confiança por parte da nação no seu govêrno. O povo saberá que a organização do Estado é um exemplo de eficiência e que a administração ministrada pelo aparelhamento do Estado poderá ser considerada como a unidade de produção mais eficiente do país. O povo saberá que o numerário de todos os contribuintes ao fisco não é disperdiçado, mas sim aproveitado, tanto quanto é humanamente possível.

O recrutamento amplo e democrático, a seleção racional mediante concursos públicos, livres e honestos, o sistema do mérito, enfim, constitui o princípio básico e o marco inicial da história dos organizados e adiantados serviços civis das nações civilizadas. E só foi possível o recrutamento em massa, sôbre largas áreas, acompanhado de seleção rigorosa e científica de grandes contigentes de servidores para - Estado, graças "à contribuição dos estudos da psicologia e da estatística para a organização de provas bem feitas". 1948 .

Belmiro Siqueira, "Revista do Serviço Público", maio e junho de 